\title{
Arteterapia y subjetividad femenina: construyendo un collage
}

\author{
Raquel GARCÍA CASASOLA ${ }^{1}$ \\ raquelgcasasola@gmail.com \\ Eva SANTOS SÁNCHEZ-GUZMÁN ${ }^{2}$ \\ evasanto@um.es
}

Enviado: 19/02/2011

Aceptado: 12/10/2011

\section{RESUMEN}

Este texto es el resultado de una investigación que ahonda, desde la teoría y la práctica, en el valor que tanto los procesos creativos como las imágenes plásticas surgidas en un espacio arteterapéutico pueden aportar a un grupo psicoterapéutico de mujeres. Para apoyar la resolución de los conflictos en este grupo se enlazan las teorías de arteterapia, la psicoterapia dinámica y la perspectiva de género. Se muestra cómo se han planteado estas relaciones a través de la exposición de tres casos clínicos que son ejemplos de los procesos psíquicos observados.

Palabras clave: Arteterapia, subjetividad femenina, psicoterapia dinámica, grupo terapéutico

\section{Referencia normalizada}

GARCÍA CASASOLA R.; SANTOS SÁNCHEZ-GUZMÁN E. (2011). “Arteterapia y subjetividad femenina: construyendo un collage". En Arteterapia: Papeles de arteterapia y educación artística para la inclusión social Vol.: 6. Páginas 87-103. Madrid. Servicios de publicaciones UCM.

\section{SUMARIO}

Introducción. Quienes construyen el collage. Un método: recortar y pegar. Buscando una base: el Arteterapia, la Psicoterapia psicodinámica y la perspectiva de género. La composición: Propuestas de taller. El dibujo de tres líneas: Exposición de casos. Una mirada al collage: Conclusiones. Referencias bibliográficas

\section{Art therapy and female subjectivity: building a collage}

\section{ABSTRACT}

This research work, from theory and practice, is based in the significance of the creative process and the art object in the art therapy sessions with a female therapeutic group. The art therapy, the dynamic psychotherapy and the gender perspective are the theory studied to help the resolution of their conflicts. We show three patient studies like example of the psychical process watched.

${ }^{1}$ Licenciada en Psicología por la UCM. Máster en Arteterapia por la Universidad de Murcia. Directora del Centro de Día para personas con Discapacidad Intelectual y Psicóloga del Ayuntamiento de Abarán (Murcia). Presidenta de MURARTT, Asociación miembro de FEAPA.

2 Doctora en Bellas Artes por la UCM. Máster en Arteterapia por la Universidad de Murcia. Artista plástica y profesora en la Facultad de Bellas Artes de la Universidad de Murcia. 
Keywords: Art Therapy, female subjectivity, dynamic psychotherapy, therapeutic group

\section{CONTENTS}

Introduction. Those who construct the collage. One method: cut and paste. Looking for a base: the art therapy, psychodynamic psychotherapy and gender. Composition: Proposals for workshop. The drawing of three lines: Exhibition of cases. A look at the collage: Conclusions. Reference.

\section{INTRODUCCIÓN}

Partimos de la hipótesis de que en un grupo de psicoterapia, que pretende solucionar los conflictos inconscientes mediante la transferencia y que utiliza la interpretación para facilitar el acceso a fantasías y mecanismos de defensa, se podría incluir un espacio de taller arteterapéutico. Su fin sería favorecer dichos procesos, ya que las producciones plásticas mejorarían la capacidad de simbolizar emociones ambivalentes, aspectos negados y defensivos, así como fantasías muy enraizadas generadoras de síntomas. Dicho espacio de taller y los señalamientos acerca de las imágenes realizadas que en él suceden, permitirían un mayor acceso a las dificultades psíquicas que presenta este grupo. El supuesto se fundamenta ante todo, en nuestro interés por investigar acerca de los progresos que las producciones plásticas aportan al proceso personal de las pacientes.

\section{QUIENES CONSTRUYEN EL COLLAGE}

Esta colaboración entre Psicoterapia y Arteterapia se enmarca dentro de las prácticas del curso de "Especialista en Clínica Psicopatológica y Psicosomática en Arteterapia" de la Escuela de Práctica Psicológica de la Universidad de Murcia. Se desarrolla con un grupo de mujeres que asisten al Servicio de Psiquiatría y Psicología del Hospital Morales Meseguer de Murcia para recibir psicoterapia. El grupo estaba coordinado por Rossana López Sabater psicoanalista y psicóloga clínica. El trabajo se realizó a través de sesiones de dos horas, un día a la semana con un total de 19 talleres, de enero a junio de 2009.

Al marco del trabajo de la psicoterapia en grupo, hay que añadir la variable importante de género que ha sido un eje fundamental en el abordaje terapéutico. Dicha perspectiva nos permitió analizar y valorar con mayor profundidad ciertas particularidades de los conflictos psíquicos y los emergentes en este grupo de mujeres.

Hemos recogido algunos artículos que exponen trabajos realizados con mujeres, con problemáticas diversas, en los que el Arteterapia ha sido utilizado como herramienta de apoyo e intervención a diferentes niveles y las cuestiones enlazadas al género aparecen en primer plano. Algunos de estos trabajos son: "Arteterapia con mujeres que han sufrido violencia de género: valor y uso del objeto artístico" de Montse Omenat en el que se utiliza la creación de imágenes como una manera de recuperar su potencial creativo (Omenat, 2006); "Mujer y Arteterapia" de Marina Ojeda y Ana Serrano y "Arteterapia con mujeres en prostitución" de Carmen Menéndez Pérez que pone de relieve cómo 
el Arteterapia hace más conscientes las carencias (y ambivalencias) emocionales, estimula la simbolización y proporciona un encuentro para la reflexión, el diálogo y la expresión a niveles muy profundos y significativos, poniéndolas en relación con sus propias biografías, ... y huellas traumáticas (Menéndez, 2009: 161)

\section{UN MÉTODO: RECORTAR Y PEGAR}

Así, el propósito de esta investigación es constatar que integrar en la Psicoterapia un tiempo de Arteterapia facilitará los procesos simbólicos y transferenciales, individuales y grupales, necesarios para la solución de conflictos. De ahí la metáfora sobre "El Collage" con la que titulamos este artículo y que utilizamos para transmitir la manera en que se han "recortado y pegado" dos maneras de trabajar la elaboración de conflictos psíquicos: uno en el que prima la palabra y otro en el que el papel protagonista lo tiene la acción en el material o la producción plástica. Esta integración de metodologías daría lugar a un nuevo encuadre y a una "imagen" más rica del grupo.

El nivel de intervención arteterapéutica estuvo orientado al cambio que, como señala Montse Omenat (2007), facilita a las pacientes ponerse en contacto con emociones profundas, conteniendo angustias y ansiedades y que propiciaría que las mujeres pudieran ir entendiendo dichas emociones en la construcción y resignificación de su historia vital.

En este sentido es importante que las terapeutas presten atención a la trasferencia, que los señalamientos se hagan con respecto al material o a las imágenes y que en el proceso creativo sean no directivas. La observación del triángulo terapéutico por parte de la psicóloga permitirá que aquellas cuestiones que se están trabajando desde la imagen, la metáfora y los símbolos a través del Arteterapia, faciliten la profundización en aspectos vivenciales y subjetivos de las participantes.

\section{BUSCANDO UNA BASE: EL ARTETERAPIA, LA PSICOTERAPIA PSI- CODINÁMICA Y LA PERSPECTIVA DE GÉNERO}

Partimos de tres perspectivas teóricas básicas a través de las que poder entender cómo se representaban y sufrían estas mujeres: El Arteterapia, la Psicoterapia psicodinámica y la perspectiva de género en psicoanálisis.

Algunas de las ideas principales del arteterapia giran en torno al valor que la metáfora tiene en las imágenes creadas en el proceso terapéutico. Tal como dice Tessa Dalley, "lo característico de una alusión metafórica es que vayan juntos lo familiar con lo infrecuente..." (Dalley, 1987) ya que es el mejor modo de poder establecer un enlace o relación entre ambas esferas. Así podría aclararse lo inusual a la luz de lo cercano. O en palabras de Goodman: "la metáfora consiste en 
enseñarle nuevos trucos a una palabra vieja, en aplicar una etiqueta antigua de un modo nuevo" (Goodman 1976)

El símbolo surgido en las imágenes, para Dalley, no plantea aparentemente una "preocupación inmediata", sin embargo se acomoda dentro "de una preocupación de más envergadura" mostrándose como una pista a seguir. Es decir, se parte de la idea de que con las imágenes se simboliza lo más difícil de expresar y se muestra a la vez que se esconde lo más resistente y lo más propio de los pacientes. Consecuentemente el arteterapia invita a una interiorización sobre sí mismo que facilita un acercamiento a esa compleja forma surgida y el arteterapeuta posibilita la confrontación y el diálogo con lo creado.

El espacio entre la persona, su producción y el otro permite la circulación de la búsqueda de la propia identidad...lo que surge de la persona y a la vez le separa de ella, que permite una comunicación poética con el otro (Dalley, 1987)

El poder realizar este taller dentro de un grupo de psicoterapia facilitó que la tarea con respecto al valor simbólico de las producciones se centrara en la subjetividad, en los conflictos y en los síntomas.

Este encuadre psicoterapéutico se estableció desde una perspectiva psicoanalítica en la que

Se busca la solución de conflictos inconscientes a través de la instauración y el desarrollo de la transferencia (en el grupo) y con el terapeuta, reactivando en el aquí y el ahora de esta relación dichos conflictos, para poder elaborarlos y afrontarlos, integrando fantasías inconscientes con defensas $(. .$.$) y conseguir que la persona que inicia esta relación psicote-$ rapéutica aprenda a nivel vivencial a hacerse cargo de sus conflictos intrapsíquicos, resolverlos y hacer frente a otros que puedan presentársele (Gamo, 1998).

En cuanto a la perspectiva de género como herramienta para realizar una escucha de los emergentes grupales, partimos de las ideas de Jessica Benjamín que, basándose en investigaciones de Stern de la década de 1980, defiende que el infante no es absolutamente simbiótico con la madre, sino que posee la capacidad de diferenciarse del mundo del otro e interesarse por él. La misma autora se interesa por la psicología del Self de Kohut, "que reinterpretó el desarrollo psíquico en los términos de necesidad del sí-mismo de encontrar cohesión y verse reflejado en otro". (Benjamín, 1996)

De estos estudios y de su nueva concepción del infante como activo, social y capaz de interesarse y responder a otros surge la "concepción intersubjetiva" que subraya que 
El individuo crece en las relaciones con otros sujetos y a través de ellos (...) y la necesidad de reconocer al otro y de ser reconocido, es básica para entender el desarrollo psíquico. Donde dos sujetos se relacionan y no solo existe una relación sujeto-objeto. (Benjamín, 1996)

Es decir esta autora, que cuestiona la conceptualización que como objetos han sufrido las mujeres tanto socialmente como en el psicoanálisis, enmarca los sufrimientos psíquicos de género tanto en la dificultad para conseguir reconocerse y reconocer a otros como en no depender excesivamente de otros y propone una visión intrapsíquica del psicoanálisis más clásico junto a una visión intersubjetiva más actual.

Los valores de género se han implementado en la psiqué de las mujeres a través de un Superyó que

Como organizador intrapsíquico se ocupa de reglamentar, mediante restricciones, mandatos e idealizaciones, todo un delicado entramado que regulará la relación de la mujer consigo misma y con su entorno, estructurando un modelo frente al cual se debatirá en permanentes comparaciones (entre los que siente y lo que debe sentir) permanentes desfases entre lo idealizado y lo percibido y que será causa de dolorosos conflictos, y sobre todo generador del casi omnipresente sentimiento de culpa (Benjamín, 1996)

Otras autoras ahondan en los valores de género como importantes estructurantes subjetivos y revisan la construcción subjetiva de la teoría psicoanalítica clásica. Así, Nora Levinton ha señalado que lo que construye la subjetividad femenina es el cuidado de la vida y las motivaciones de apego que surgen del imaginario social en torno a la mujer, construido por el orden simbólico masculino, sobre experiencias y deseos de los varones, y en el que no se ha tenido en cuenta este orden interactivo-subjetivo. Esto deriva, como cita González de Chávez, en que "la mujer hace del amor su trabajo y la pérdida de amor es el principal causante de angustia en las mujeres" (González de Chávez, 2000)

Esta angustia es causante de innumerables síntomas psíquicos y somáticos como depresión, ansiedad, diversas álgias, hipocondrías, hiper adaptaciones, miedo al éxito, etc., manifestándose a través de idealizaciones de la maternidad y ambivalencias negadas con respecto a ella: idealización del amor y el saber del otro; negación de su deseo y dificultades para realizar investimientos narcisistas positivos de sí mismas, a la vez que una construcción narcisista que gira en torno al deseo del otro. Unos mandatos superyoicos muy exigentes con respecto a estas tareas que generan culpa, negación de su agresividad y dificultades para el proceso de individuación y por tanto para afrontar los conflictos.

El principal propósito del tiempo de Arteterapia, dentro de este espacio "Psi," consistiría en promover y acompañar el proceso de producción de imágenes que 
sirvan para simbolizar y metaforizar conflictos, como hemos señalado anteriormente. Pero también el bosquejo de nuevas imágenes propias con las que identificarse positivamente. Con ello, instaurar un espacio de "hacer y crear" que facilite el proceso de apropiación de un discurso subjetivo. Invitarles a ser generadoras de imágenes y facilitar la elaboración de la imagen de sí mismas permitiéndose despojarse de idealizaciones, "lo que deben ser, lo que no pueden ser "y elaborando imágenes propias a través de procesos creativos, de "lo que son y lo que pueden llegar a ser".

\section{LA COMPOSICIÓN: PROPUESTAS DE TALLER}

Al tratarse de una investigación teórico-práctica, estas teorías han ido apoyando la estructura de la investigación, si bien la organización, desarrollo y observación de cada uno de los procesos individuales y grupales surgidos en los talleres han guiado el curso del trabajo.

Presentamos a continuación cómo se han conjugado las propuestas de taller. La definición de cada una de ellas surge de la observación de los procesos, como las pistas a seguir que señalaba Dalley, y de la necesidad de ir introduciendo materiales o consignas que favorezcan la resolución de los conflictos. Esta observación es llevada a cabo durante y después de cada sesión, en una reflexión conjunta entre la psicóloga y las arteterapeutas. Debido a la dificultad de separar procesos, imágenes, emociones y comentarios, y la imposibilidad de distribuirlas en apartados, ya que cada uno se ha dado en circunstancias concretas e irrepetibles, hemos optado por presentar un primer bloque con aquellas que pueden ayudar a comprender el proceso seguido, y una segunda parte con el proceso completo de tres de las pacientes.

\section{El primer encuentro}

Una de las cuestiones previas era cómo introducir el taller de Arteterapia en un grupo de psicoterapia que ya había comenzado, nos parecía importante iniciar con una propuesta que integrase tres conceptos: la relación grupal, el espacio y la creación plástica. El primer material fueron las madejas de lana, con ellas caminarían por el taller, entre las sillas, entre ellas. Esta tarea les llevaría poco tiempo y podríamos permitir un turno de palabra largo como al que estaban acostumbradas. En esta sesión comenzaron a surgir las primeras representaciones: se marcó el espacio terapéutico al iniciar el dibujo en la puerta de entrada; se hicieron presentes los vínculos con el otro al atarse a la silla de una de las compañeras tirando la suya propia; apareció la maternidad cuando protegen un ovillo rosa como símbolo de la hija o señalan a la terapeuta envolviendo su silla con la lana. También aparecieron algunos recelos ante el Arteterapia: "esto no tenía sentido" o "me ha parecido una pérdida de tiempo", comentaron algunas y otras confirmaron. Teníamos ante nosotras unas pacientes que, si bien hasta ese momento tenían dificultad para separarse de la vivencia de lo concreto, habían sido capaces de co- 
menzar a "dibujar" en el espacio sus miedos, sus deseos y sus modos de vivir determinadas relaciones con sus grupos y personas de referencia, pero sobre todo habían podido manifestar sus desconfianzas ante lo realizado.

\section{Acercándonos a la creación: la reflexión sobre sí mismas}

A partir de aquí las propuestas continúan con materiales y consignas concretas. Una de ellas será extender plastilina sobre un cartón y marcar huellas con objetos que suelen llevar encima, otra trabajar a partir de las siluetas de sus manos. De este modo podíamos favorecer el acercamiento a la creación sin producir demasiada ansiedad ante dudas que sobre su capacidad creativa pudiesen surgir. Ambas propuestas abrían un espacio para que se generara una reflexión sobre sí mismas, sobre sus objetos, su propio cuerpo y su manera de representarse.

Significativamente los objetos que surgieron fueron: anillos de casadas, la foto de su hija, la llave de su casa, la cruz... y junto a sus manos aparecieron las de sus maridos, hijos e hijas o las de las personas que les iban a "echar una mano". A través de estas imágenes, de las palabras y de los señalamientos de las arteterapeutas, se comenzaron a establecer nexos entre las relaciones que mantenían, su modo de posicionarse ante éstas y el malestar y los síntomas que se derivaban de ello.

\section{La expresión en el material}

Dependiendo del momento o el proceso grupal, este tipo de propuestas determinadas y dirigidas, se fueron alternando con otras menos estructuradas que se centraban en el material, bien para que tomaran más relevancia los conflictos individuales y subjetivos de cada una de las participantes, o bien para favorecer momentos grupales de cohesión e identificación grupal que permitieran continuar avanzando sin angustia.

Se ha trabajado con materiales (determinados o libres) sin consigna cuando los emergentes empiezan a hablar de cómo poner en juego el deseo propio. Un ejemplo de ello es la utilización del papel de seda de colores. Este material posee una gran sutileza tanto por su tacto como por su sonido. Les permitió crear algunos collage en los que se mantenían campos diferenciados de colores puros: banderines, personajes... Pudieron arrugarlo, doblarlo o rasgarlo para hacer creaciones más corpóreas: lazos, un vestido, o un pompón. Pero más allá de estas posibilidades técnicas destacamos la cualidad de este material para evocar emociones y poder simbolizarlas. Un ejemplo fue la confección de un pompón a través del cual la paciente recordó momentos de tranquilidad. Debemos señalar que esta paciente manifestaba una dificultad de concentración, sin embargo se dedicó afanadamente en la elaboración de este objeto, lo que le permitió un proceso contenedor. Para otra, los banderines cortados en papel de seda adornaban el recuerdo de fiestas de cumpleaños narradas como idealizaciones del pasado. Otra de las imágenes mostraba franjas de color, a modo de personajes, en las que se 
resaltaba la relación y situación de ellos en la composición. También surgió la creación de un vestido a partir del recuerdo que otra paciente tenía de los momentos vividos con su padre, recién fallecido, durante los que confeccionaban adornos para las zambotas de navidad. Esa misma imagen se transformó, mirada desde otra perspectiva, en un vestido con el que la paciente se vestiría en la actualidad.

\section{El momento de pensar la historia}

Pronto observamos que las continuas idealizaciones se nos presentaban como repeticiones a través de las cuales podríamos promover, como señala Luís Hornstein, un diálogo entre el pasado y el presente y de este modo hacer historia con la repetición, tomando esas miradas hacia el pasado como impulsoras de futuro (Hornstein,1992). Se pudo trabajar con ello al representar "caminos" en los que se destacaron historias felices pero también truncadas con objetos pegados, cambios de color o baches que en la mayoría de los casos habían sido generadas por la caída de dichas idealizaciones: maltrato, separaciones, maternidades complicadas... Pero también se facilitó la posibilidad de reparación al reelaborar o transformar obras anteriores pudiendo dar más tiempo a la elaboración de aspectos significativos. Este diálogo entre pasado y presente fue trabajándose de manera explícita e implícita durante todas las sesiones, ya que

...convertir la historia en pasado permite un futuro que no sea pura repetición, sino que se afirme como diferencia y que aporte la diferencia. Recordar es ya un comienzo de olvido en la medida que desactualiza al pasado temporalizándolo (Hornstein, 1992)

\section{La vivencia de conflictos}

Por otro lado, se propuso un trabajo en grupo cuando se empezaba a ver dificultades para entrar en conflicto. Entendimos el grupo como un laboratorio en el que se reproducían las emociones que, ante las experiencias de relación externas, vivían las pacientes. De este modo, al observar un exceso de cuidado en el manejo y en el compartir de los materiales; una estructura en el turno de palabra estancada en los comentarios de la propia obra (en ocasiones excesivamente largos) y un modo muy respetuoso de mantener los turnos de palabra, vimos oportuna la introducción de este trabajo en grupo. Sobre la mesa extendimos papel continuo blanco y les ofrecimos lápices de color, pinceles y guaches. En ese momento comenzó el conflicto entre reservar el espacio propio o trabajar por toda la superficie. Excepto dos, todas tomaron los pinceles. "A" inició una conquista del papel, invadiendo los trabajos de las demás, algunas se unieron a ella, el resto señaló que no les molestaba. Las otras dos, cogiendo los lápices de color, mantuvieron un pequeño espacio personal de finos trazos: una dibujó una casa en ruinas (emoción que sentía en ese momento) y la otra un espacio para tomarse un 
café tranquila y luego echarse a descansar. A partir de aquí el grupo empezó a nombrar ciertas emociones, tales como la dificultad para mantener un espacio vital y psíquico propio y que les producían dificultades en sus relaciones.

\section{La retrospectiva}

Como elemento relevante de esta práctica cabe destacar "la retrospectiva" de los trabajos realizados como técnica que ha permitido al grupo elaborar nuevos significados sobre imágenes pasadas a través de una serie de repetición en la mirada pero reactivando lo actual de la transferencia. No se propuso como un cierre del taller sino como un punto de reflexión tras el cual vendrían al menos tres sesiones. Pero la riqueza de la elaboración que generó hizo que se extendiera durante tres días.

Durante estas sesiones algunas no reconocían ciertos dibujos como propios, les parecían infantiles, o señalaron cosas muy diferentes de lo que en su momento significaron. Por ejemplo mencionamos un lapsus: Una de las pacientes, al observar el trabajo que hizo de la representación del grupo se identifica en este momento como la que está en el centro, dentro de una estrella. Esta mujer nos acababa de solicitar una evaluación final, nuestra valoración de cómo habíamos visto nosotras su progreso. Instantes después dice. "¡Ah no! ¡Si es la psicóloga! (la que está en el centro del grupo en su dibujo) .Una compañera le señala "ya no te hace falta una evaluación, tu te has puesto en el sitio de la sabe".

En definitiva, podemos señalar que el discurrir de los talleres ha ido transitando entre propuestas más contenedoras (huellas, caminos, refugios...) que han permitido reconocer al otro y ser reconocido con más facilidad y otras en las que la libertad del planteamiento o de la elección del material (papel de seda, barro, manchas de color, collage) han favorecido la elaboración de ambivalencias emocionales y conflictos, pudiendo acceder a niveles profundos gracias al apoyo psicológico.

\section{EL DIBUJO DE TRES LÍNEAS: EXPOSICIÓN DE CASOS}

Vamos a comentar tres casos que son ejemplos de los aspectos más significativos que hemos observado en este grupo de mujeres: la idealización del otro, recomponer su imagen de madres y saber pensarse por sí mismas.

\section{Idealización del otro}

M. es una mujer de unos 50 años, que ha sufrido una separación y con ella la pérdida de todos sus bienes. Hija única, en la actualidad vive sola. Tiene cinco hijos con los que existen dificultades de relación. En el espacio terapéutico "inicia un viaje" siempre hacia lugares ideales: el sol, una isla, la cima de una montaña, el último rellano de una alta escalera... Mientras, va narrando su impresión de que tanto su ex marido, como sus hijos e hijas, el resto del grupo o las terapeu- 
tas, tienen una situación mucho mejor que la suya. Reconoce su imposibilidad para "nadar, subir escaleras o salir del círculo" en el que se halla encerrada "dando vueltas alrededor de lo mismo y no encuentro salida". (Imagen 1) En sus imágenes plásticas también aparecen barcos que se hunden y náufragos pidiendo auxilio.

En la "fiesta de cumpleaños" que hemos señalado anteriormente, muestra una gran idealización del padre que tiene que ver con la transferencia que deposita sobre las terapeutas dibujándolas después como ángeles. (Imagen 1)

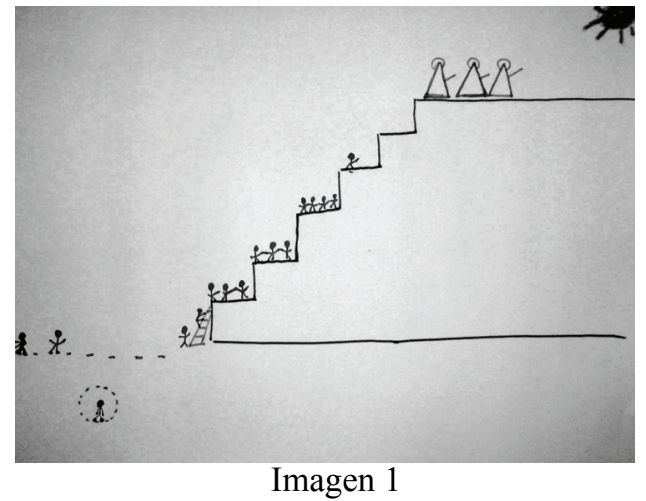

Pero también observamos una nostalgia del pasado, que prácticamente todas comparten, una nostalgia dibujada que les permitirá comenzar a construirse un futuro.

Junto a estas nostalgias del pasado aparece la idealización del amor. M. nos muestra en la realización de su camino, cuatro corazones del mismo tamaño ordenados en diagonal descendente. Los caracteriza como distintas etapas de su vida: su infancia y juventud felices y cantando; su enamoramiento; una etapa cubierta con una nube negra y en la actualidad un corazón roto. A pesar de señalarle que este corazón no es el mismo, ya que está curado con tiritas, ella sólo puede ver la herida que reparan, y no la posibilidad de reparación que ha representado. Una cura que ella niega poder hace sola. No puede asumir en ese momento que las etapas de la vida sean diferentes e idealiza a un amor que la salve: "Deseo enamorarme de un alma y no de la belleza física de un hombre".

Esta paciente muestra de manera reiterada a lo largo de la terapia una conducta cerrada ante los señalamientos que las terapeutas y el resto del grupo le sugiere. Siempre los rechaza, niega o ignora. Sin embargo pudo reaccionar ante el dibujo en el que deseaba subir una gran montaña para encontrarse con sus hijos del pasado. "Subir a esa montaña le supondrá una gran decepción, se va a dar un batacazo", señala la psicoanalista. Ante esta realidad ella se siente agredida, está a punto de abandonar el grupo, pero gracias a que continúa puede comenzar a elaborar su conflicto. 
Y lo reinicia dibujando su propia imagen representada en la parte derecha del papel. Es una imagen volátil, casi de vapor, con una tímida base marcada con una interrogación que a menudo aparece en sus trabajos a modo de señal de identidad o como un reclamo para ser atendida. Sin embargo es una imagen del mismo tamaño y en la misma posición que la del grupo que siempre idealiza. (Imagen 2)

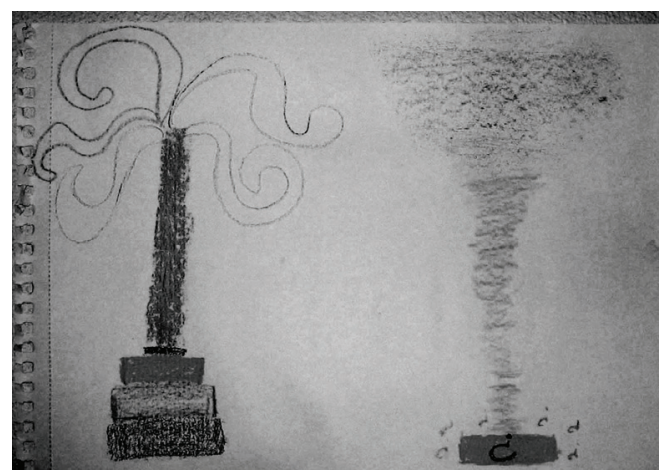

Imagen 2

Posteriormente a estas sesiones M. puede realiza un viaje real, en los próximos días viajará a Canarias, nos lo cuenta entusiasmada al poder dar este gran paso. Se les ofrece barro para trabajar y ella representa de nuevo un viaje en barco, en este caso las olas del mar se han convertido en serpientes ("sois vosotras el otro día", dice a las terapeutas refiriéndose al día en que se sintió agredida). Llega a una isla en la que hay un gran ángel sobre una montaña. Pero dice: "me ha salido un falo y he querido disimularlo, me ha dado mucha vergüenza". Así mismo en la playa modela un pequeño personaje nadando, "en principio era un hombre, pero luego se convierte en mujer, soy yo que estoy nadando y buceando". En esta imagen plástica creemos que se representa una humanización y apropiación de su deseo: frente a un ángel estático se sitúa un falo como símbolo de deseo, y una figura humana con capacidad de moverse y disfrutar. En la retrospectiva se le señaló cómo aquella naufraga de sus primeras representaciones se fue convirtiendo en una mujer nadando y buceando sin ahogarse.

\section{Recomponer la imagen de la maternidad}

C. es una mujer con una maternidad muy conflictiva; comienza las representaciones hablando de este conflicto y lo traerá en todas las sesiones.

Ante la sugerencia de dibujar un paisaje, representa su casa de campo con árboles y un sol, un lugar placentero para ella. Sin embargo, por la chimenea sale un humo negro que impide que el sol la ilumine. En la sesión siguiente partimos de este paisaje. Sin recortar ni manipular el trabajo anterior, vuelve a representar su casa. Se la observa angustiada durante el trabajo. La casa ahora explota y su 
hijo es el detonante de esa explosión. Nos lo describe como un pequeño delincuente que la hace sufrir.

La representación vertical de su "Camino" se inicia con la felicidad de su matrimonio cuando ambos deseaban ser padres. Así, un corazón enmarca la figura de la pareja en primer lugar sobre un gran espacio coloreado de rojo. Posteriormente, el rojo se intensifica y sobre él dibuja "mi estrella" (el hijo), para continuar con un tramo del camino atravesado por diferentes franjas negras y grises como "el momento presente". En la parte superior, sobre un fondo verde nos muestra el futuro en el que de nuevo aparece la representación de la pareja sola. Se le pregunta que dónde está su hijo y ella responde "en el colegio supongo", "Pero ¿dónde está en el dibujo?", se queda pensativa. Los señalamientos en esta representación giraron en torno a la paradoja de una estrella brillante en un fondo tan negro.

$\mathrm{Su}$ hijo como estrella aparece de nuevo en su autorretrato realizado en plastilina. Ella es una figura pequeña que lleva clavada en la cabeza un palillo y en el extremo una estrella. La estrella se repite una vez más ante un dibujo libre (Imagen 3).

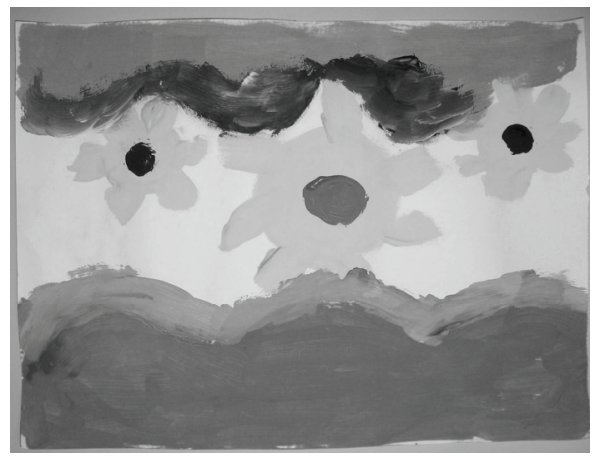

Imagen 3

Esta dicotomía entre "la que debe ser" y "la que podría ser" la presenta en dos. En la parte superior colorea una nube negra y en la inferior un mundo rosa y verde, entre ambas representa a su marido, a ella y a su hijo. La pareja son de un mismo tamaño, sin embargo el hijo-estrella es más grande y parece ser el que debe sostener la situación, es el que está directamente conectado con ambos mundos, parece ser que es del que depende que la familia esté en un lado o en el otro (rosa o negro). Se le señala cómo el hijo parece que está cercano a ambos lados. La nube negra fue pintada sin limpiar bien el pincel del color de rosa y al ir secándose, entre el negro aparecían líneas rosas, cualidades intermedias en el color y matices que suavizan el contraste. Al acabar la sesión dijo "mira el negro no es tan negro".

En una sesión posterior se les ofrece poder elegir material y soporte. C elige lápices de color para dibujar sobre cartón. En sesiones anteriores habíamos hablado de la importancia al elegir el soporte, porque a menudo cargamos mucho 
en superficies que no resisten (un modo metafórico de hablar de las cargas que asumen). Con esos lápices de colores intenta dibujar a su hijo pero tiene gran dificultad, da la vuelta al cartón e intenta recomponer su imagen de madre. Y llorando reconoce que lo que le hace sentirse mal no es el niño, sino lo que los demás piensan de este niño. Se siente juzgada y teme fallar. Es la represión del superyó femenino que antes describíamos, el que regula la relación de la mujer consigo misma y con su entorno. El superyó femenino que estructura un modelo ante el cual se plantean continuamente comparaciones que van a revelar desfases entre lo idealizado y lo percibido. Unos desfases que, en este caso, aún están por elaborar.

\section{La subjetividad como valor o pensar por sí mismas}

A. de 55 años tiene un conflicto debido a su separación. Ha pasado por varias terapias. Por su historia, sus síntomas y su modo de actuar, podríamos pensar que se ha construido un falso self en el sentido que Jessica Benjamín recupera de la definición de Winnicott: "el sí mismo obediente, adaptativo que ha evitado el caos aceptando la dirección y el control del otro, que ha mantenido la conexión con el objeto, renunciando a la exploración, a la agresión y la separatividad" (Benjamín, 1996)

Comienza el grupo partiendo de una imagen estereotipada del concepto de equilibrio, sus lanas dibujan en el tablón de anuncios del aula unos triángulos a los que nombra con su nombre técnico: "equiláteros" .Necesita utilizar las palabras concretas y exactas para nombrar lo que le ha sucedido durante la semana, así como en sus trabajos. Sus explicaciones sobre las producciones plásticas que realiza muestran una gran ansiedad por nombrarlo todo, por decirlo todo, en un temor a ser inexacta. Tiene dificultad para crear libremente, para pensar por sí misma. En una ocasión llega a decir: "somos esposas de, madres de, y siempre seremos madres de..."

Esta dificultad para validar los pensamientos propios desde sí misma se presenta, en uno de los primeros trabajos, a través de un intento de fórmula matemática que se sitúa por encima de sus emociones. Poco a poco va dejando de lado los estereotipos y van apareciendo los deseos de representar sus emociones. De este modo, el camino "se hace al andar" y señala que no "quería hacer el típico camino alargado", muestra un interés por algo diferente a lo que tienen que ser las cosas y mediante la técnica de la construcción (podía haber elegido otra) construye este camino que representa la agresividad que ella lleva dentro y no puede manifestar. (Imagen 4) 


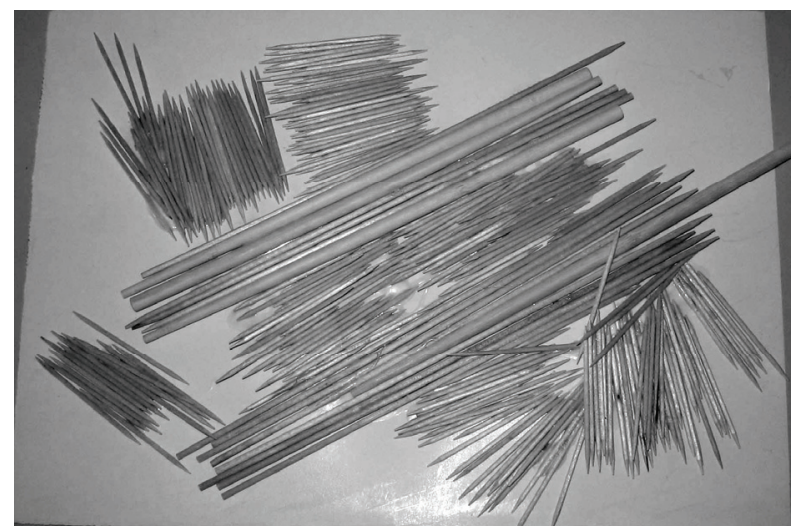

Imagen 4

Esta dicotomía entre "la que debe ser" y "la que podría ser" la presenta en dos imágenes que constituyen su autorretrato, imágenes diferentes pero que están atravesadas por un eje a modo de columna vertebral. En una erguida, sujetando todos los problemas y en una sucesión constante de color y forma; la otra figura cae una y otra vez. Es así como se siente, mucho más vulnerable.

Así, va pudiendo abordar qué es la emoción en ella, y cómo integrarla en su vida. Continuamos trabajando con el color (imagen 5). Sobre papel de dibujo pintarán con guache. Supera las dificultades que ella señala: "el papel muy blando y el pincel muy duro", reconoce que su creación surge de una base caótica pero que es capaz de limpiar y ordenar puntualmente. Nos ofrece una imagen muy expresiva porque representa este conflicto entre el caos y el equilibrio. En el siguiente trabajo con color, dejará caer la pintura con libertad y expresión.

En la retrospectiva nos dice: "el equilibrio no existe, tengo que buscar mi por qué y no el por qué. Sé que puedo cometer errores y puedo vivir". "Yo tengo que poner mi propio eje, en la vida no hay un eje para todo, sino el mío propio". "Planeas una cosa y luego es otra". "No me he dado cuenta, pero he estado trabajando con las emociones".

\section{UNA MIRADA AL COLLAGE: CONCLUSIONES}

Este marco de grupo "psico-arte-terapéutico" ha facilitado que las mujeres comprendieran que las imágenes eran representaciones de aspectos de sí mismas y se han esforzado porque esto sea así. La creación de imágenes les ha invitado a realizar un trabajo por explicarse que les ha ayudado a elaborar un discurso sobre sí mismas, sobre cada una de ellas y sus conflictos a nivel subjetivo. Dicho trabajo es más dificultoso sin el apoyo del símbolo y la metáfora que confiere la creación plástica y que se ofrece en el espacio del Arteterapia. En este sentido las imágenes creadas han actuado como un "auxiliar del yo" ya que se han apoyado en ellas para verbalizar las cuestiones más difíciles y dolorosas de explicar. 
La transferencia con el grupo y con las terapeutas ha sido más explícita a través de las imágenes, sobre todo en cuestiones muy costosas de abordar en todos los grupos como lo referido a la idealización que se hace de los coordinadores y las dificultades que supone para la propia cura la idealización de éstos. A través de las imágenes ha sido más sencillo acceder a estos aspectos conflictivos. La psicóloga pudo constatar que en comparación con otros grupos esta cuestión se ha abordado de mejor modo y más rápidamente que en otros grupos donde no hay Arteterapia. Así mismo el trabajo de desidealización se ha comenzado antes que en otros grupos.

El trabajo de arteterapeutas y psicoterapeuta ha sido a diferente nivel. Ambas realizábamos señalamientos: mientras que las arteterapeutas señalábamos cuestiones que tenían que ver con las imágenes o con las actitudes con respecto al crear o relacionarse con los soportes o el material, la psicóloga podía vincular estas imágenes con aspectos más generales de la historia de las pacientes. La transferencia que se hacía a las imágenes se relacionaba con fenómenos grupales o con significados subjetivos de cada una de ellas, dando lugar a la apertura de nuevos significados.

Por lo tanto, al hacer posible vincular las imágenes con las transferencias grupales y con la historia de cada una de las pacientes, se ha facilitado una "puesta en escena de uno mismo" (Klein, 2006) y así pudieron surgir imágenes nuevas y propias con las que identificarse.

El tiempo de silencio y producción les ha ayudado a centrar los aspectos significativos que se tratan en las sesiones y por lo tanto a hacer más eficaz la tarea del grupo, potenciando la introspección en la elaboración del proceso terapéutico. Estos tiempos o no se presentan, o son cortos y escasos, o son recursos del paciente en los espacios terapéuticos.

El insertar, dentro de un encuadre de grupo psicoterapeútico, un espacio de trabajo arteterapeútico ha permitido observar las interrelaciones entre estos dos modos de abordaje del conflicto psicológico, realizar un trabajo conjunto entre las profesionales implicadas, colaborando en un trabajo interdisciplinar estrecho, $\mathrm{y}$ ofrecer a las pacientes un lugar estable en el que trabajar sobre su propia identidad y desarrollo psíquico.

Un aspecto no previsto en los inicios de la investigación es el gran valor observado en la retrospectiva. Hemos experimentado cómo el grupo, a través de la técnica de retrospectiva, puede "ver" más claramente lo negado o lo no identificado, al descubrir partes de ellas que no se vieron o que son difíciles de integrar en los primeros momentos de la terapia. La posibilidad de conferir a las imágenes diversos significados, emociones o sentimientos nos hizo pensar en la gran capacidad de contención que poseen las imágenes creadas. En éstas han podido depositar gran carga emocional y simbólica sin quedarse atrapadas, comprometidas o cuestionadas superyoicamente por lo dicho sino más bien, pudiendo transitar y resignificar sus producciones como un modo de "autorizarse", en el sentido de autor, y por lo tanto hacerse cargo de sus ambivalencias. 
Pensamos que la presencia de dos arteterapeutas y una psicóloga ha facilitado un diálogo más abierto sobre sus obras, permitiéndose con más libertad hablar grupalmente.

Por último queremos recoger las palabras de la coordinadora del grupo Rossana López Sabater: "el Arteterapia les ha ayudado a historizarse, a poder mirarse en una trayectoria vital en la que no ha sido posible mirarse anteriormente. Podían verse, sí, pero solo a través de esos lugares superyoicos que se han señalado." 


\section{REFERENCIAS BIBLIOGRÁFICAS}

BENJAMIN, JESSICA. (1996) Los Lazos de Amor. Psicoanálisis, feminismo y el problema de la dominación. Buenos Aires, Paidós. Psicología profunda.

DALLEY, TESSA. (1987) El arte como terapia. Barcelona, Herder, Biblioteca de Psicología.

FREDEN, LARS. (1986) Aspectos psicosociales de la depresión. México, Fondo de cultura económica.

FIORINI, HECTOR. (2007) El Psiquismo creador. Vitoria-Gasteiz, Agruparte.

GONZALEZ DE CHAVEZ FERNÁNDEZ (2000) "El ideal maternal y el sufrimiento psicosomático en las mujeres". En II Jornadas Salud Mental y Género. Madrid 9 y 10 de Octubre de 2000. n ${ }^{\circ}$ 32. Pág. 31. Madrid. Debate ed.: Instituto de la Mujer.

HORNSTEIN, LUÍS. (1992) "La iniciación del tratamiento. La historia por hacer". En Zona erógena. $N^{o} 11$. Buenos Aires

KLEIN, JEAN PIERRE. (2006) Arte Terapia, una introducción. Barcelona, Octaedro.

LEVINTON, NORA. (1999) "El superyó femenino". En Aperturas psicoanaliticas. Revista internacional de Psicoanálisis. $N^{\circ} 1$. Madrid.

MENENDEZ PÉREZ, CARMEN. (2009) "Arteterapia con mujeres en prostitución”. En Encuentros con la expresión. Revista de arte-terapia y artes. Vol II. Pág. 105. Mancomunidad del Valle de Ricote. Murcia

OMENAT, MONTSE (2006) "Arte terapia con mujeres que han sufrido violencia de género: Valor y uso del objeto artístico" en Arte terapia, 225-261. Murcia. Universidad de Murcia.

\section{BIBLIOGRAFÍA NO REFERENCIADA}

OMENAT, MONTSE (2007) Apuntes para el curso de Especialista en creación y mediación plástica. "Niveles de intervención en arteterapia". Escuela de práctica psicológica. Universidad de Murcia. 